Giroux, J.-F. 2020. Book Review: Second Atlas of the Breeding Birds of Southern Québec. Avian Conservation and Ecology 15(1):5. https://doi. org/10.5751/ACE-01513-150105

Copyright (C) 2020 by the author(s). Published here under license by the Resilience Alliance.

Invited Essay or Review

\title{
Book Review: Second Atlas of the Breeding Birds of Southern Québec
}

Jean-François Giroux ${ }^{l}$

${ }^{1}$ Université du Québec à Montréal

\section{Revue d'un livre : Deuxième atlas des oiseaux nicheurs du Québec méridional}

Key Words: Atlas; book review; Québec

Published nearly 25 years after the first atlas (Gauthier and Aubry 1996), the second atlas of the birds breeding in southern Québec is now available in French and English (Robert et al. 2019). The book edited by Michel Robert, Marie-Hélène Hachey, Denis Lepage, and Andrew R. Couturier totals 720 pages, 458 photos, 1092 maps, 494 graphs, and 39 other tables or figures.

The first reaction when looking at this atlas is how attractive the book is. Its graphic design and refined layout motivate any readers to go through the book. The editors have chosen a streamlined contemporary typography that makes the text easily readable and not too compact despite the abundance of information. Of course, a book on birds must include nice bird photographs and this atlas has benefited from the contribution of nearly 100 photographers who provided free of charge exceptional pictures of birds and their habitats. The editors even thought of adding a ribbon page marker, which helps readers returning to a specific marked page.

The polished design of the presentation is not the only characteristic of this atlas. Most importantly, its scientific content is noteworthy. The first section of the book consists of seven chapters that describe the methodology, a summary of the results, a guide to interpret the species accounts, and a comprehensive analysis of changes in habitat and bird distribution between the first and second atlas. A second section presents detailed accounts for 251 species (and two hybrids) breeding in Québec south of $50.5^{\circ} \mathrm{N}$, which roughly corresponds to the inhabited region of the province. Each account, displayed on two facing pages, is readily understandable. The text on the left describes the distribution and abundance, status, and data summary of each species with supporting maps and charts on the right page. The last section includes appendices presenting a calendar of nesting chronology, a table with population trends for 225 species breeding in southern Québec based on the North American Breeding Bird Survey, a list of the English, French, and scientific names of the animal and plant species cited in the text, and a useful glossary. Finally, a list of more than 1000 references cited in the text is presented.

The second atlas is based on more than 100,000 hours of fieldwork conducted between 2010 and 2014 by 1805 observers. Atlassers filled out 31,679 data forms and reported 566,834 bird records in

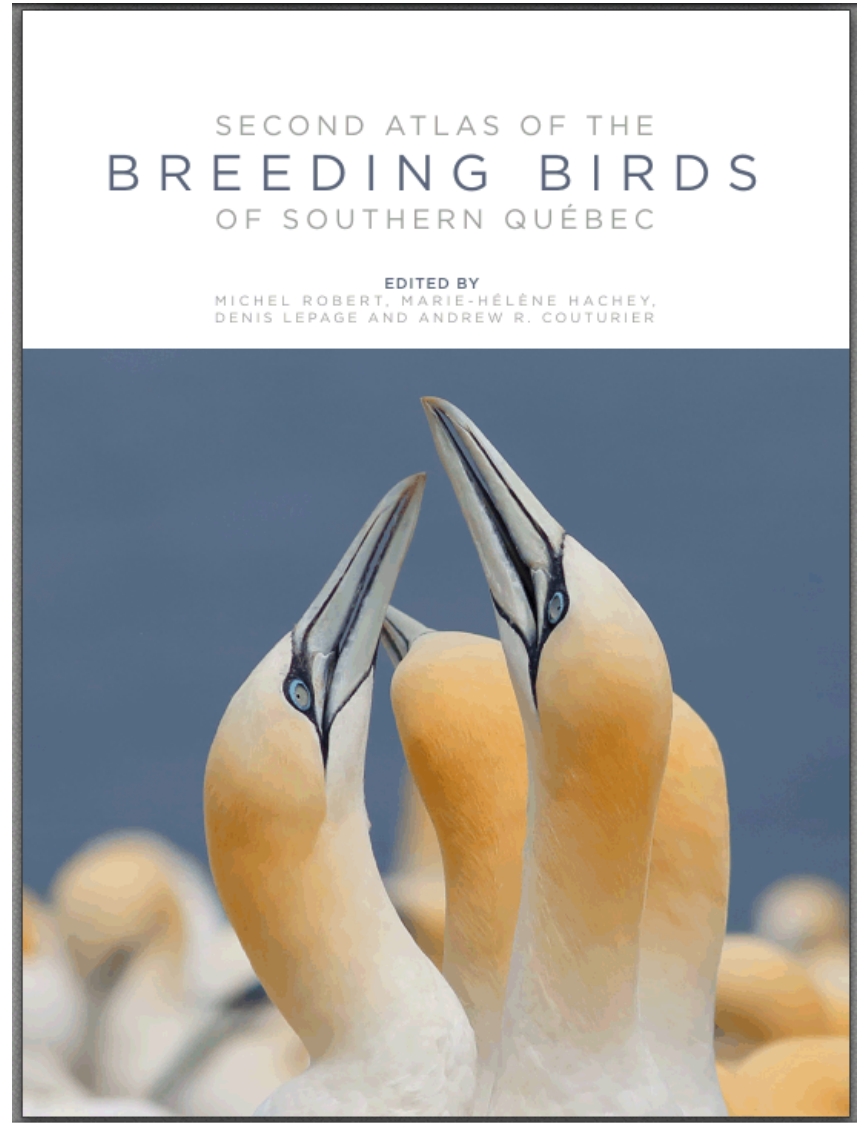

$403310 \times 10 \mathrm{~km}$ survey plots. This represents $64 \%$ more plots and a $44 \%$ increase in survey effort compared to the first atlas (19841989; Gauthier and Aubry 1996). Observers used standardized codes and levels of certainty to determine breeding evidence of species in each plot. This provided the basic information to produce typical bird atlas maps for 248 species. The frequency of breeding evidence categories for each species is also shown in a chart with histograms. Finally, the occurrence frequency of these species in each bioclimatic domain of southern Québec (sugar 
maple-bitternut hickory, sugar maple-basswood, sugar mapleyellow birch, balsam fir-yellow birch, balsam fir-white birch, and spruce-moss) is presented in bar graphs.

The probability that a species would be detected in a plot after 20 hours of effort was estimated with generalized additive models using a binomial distribution. These probabilities were calculated for 161 species for the two atlas periods and shown on distinct maps. A third map was also produced with the resulting variation between the first and second atlas. The editors acknowledged caveats inherent to this approach because of, for instance, increased knowledge of participants, use of modern technologies for broadcasting playbacks, and better access to certain portions of the boreal forest through logging roads.

A valuable addition to the second atlas project was the completion of 34,502 five-minute point counts by competent observers in a sample of survey plots. These data were used to model relative abundance of species detected on one or more counts in at least 50 plots. Relative abundance maps were then generated for 115 species, mainly passerines. In many cases, these maps provide more accurate estimates of how numbers of a species are distributed than the probability of observation maps. In summary, the way that the data were compiled and analyzed to present the current distribution of Québec breeding birds and to compare results between the first and second atlas could become a model for other atlases.

The atlas itself cannot be fully evaluated without considering the database created to produce the book. Data from both atlases can be downloaded free from "NatureCounts" (https://birdscanada. org/birdmon/default/main.jsp) of Bird Studies Canada. An example of how these data can be used is the study by Regos et al. (2018) who examined the impacts of land-use changes on bird communities using species distribution models. The database can also be queried through different interactive tools available on the Atlas web site (https://www.atlas-oiseaux.qc.ca/index_en.jsp. For instance, distribution of each species can be compared between the first and second atlas with results shown on maps or in tabular form. This is particularly useful for presentations during ornithology classes or public lectures.

This second atlas is an essential source of information for professional ornithologists, especially for consultants who must conduct environmental impact assessments in Québec. It will also be useful for amateur bird watchers who want to learn more about the abundance and distribution of birds breeding in southern Québec. Finally, the book is very gratifying for all observers who conducted bird surveys in one or more plots during the five years of the project.

The book is copublished by the Canadian Wildlife Service of Environment and Climate Change Canada, Regroupement QuébecOiseaux, and Bird Studies Canada. The hardbound copy is available for Can $\$ 90$ and the E-book (PDF version) for Can $\$ 65$ in bookstores, nature and wildlife shops, and online from QuébecOiseaux (https:/quebecoiseaux.org/index.php/en/store/ books/second-atlas). Interestingly, profits from the sale of the atlas will be invested in a fund that supports bird studies, habitat protection initiatives, and activities that promote bird watching. This is a remarkable example of how citizen science can ultimately contribute to the science of ornithology and bird conservation.

Responses to this article can be read online at: http://www.ace-eco.org/issues/responses.php/1513

\section{LITERATURE CITED}

Gauthier, J., and Y. Aubry, editors. 1996. The breeding birds of Québec: atlas of the breeding birds of southern Québec. Association Québécoise des Groupes d'Ornithologues, Province of Québec Society for the Protection of Birds, and Canadian Wildlife Service. Environment Canada, Québec region, Montréal, Québec, Canada.

Regos, A., L. Imbeau, M. Desrochers, A. Leduc, M. Robert, B. Jobin, L. Brotons, and P. Drapeau. 2018. Hindcasting the impacts of land-use changes on bird communities with species distribution models of bird atlas data. Ecological Applications 28:1867-1883. https://doi.org/10.1002/eap.1784

Robert, M., M.-H. Hachey, D. Lepage, and A. R. Couturier, editors. 2019. Second atlas of the breeding birds of southern Québec. Regroupement QuébecOiseaux, Canadian Wildlife Service (Environment and Climate Change Canada), and Bird Studies Canada, Montréal, Québec, Canada.
Editor-in-Chief: Keith A.Hobson
Sponsored by the Society of Canadian Ornithologists and Birds Canada

Parrainée par la Société des ornithologistes du Canada et Oiseaux Canada

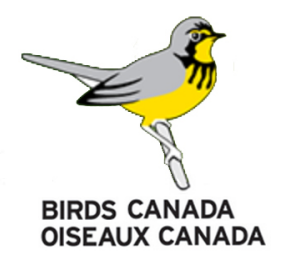

